\title{
The Kinetics and Mechanism for the Oxidation of Nicotinic Acid by Peroxomonosulfate in Acidic Aqueous Medium
}

\author{
Anju Agrawal, Riya Sailani*, Beena Gupta, C. L. Khandelwal, and P. D. Sharma \\ Department of Chemistry, University of Rajasthan, Jaipur-302055 (India) \\ *Email: l.p_riya@yahoo.co.in
}

(Received February 2, 2012; Accepted March 21, 2012)

\begin{abstract}
The kinetics of oxidation of nicotinic acid by peroxomonosulfate (PMS) has been studied in acetate buffers. Stoichiometry of the reaction corresponds to the reaction of one mole of the oxidant with a mole of nicotinic acid. $\mathrm{N} \rightarrow \mathrm{O}$ product has been confirmed both by UV visible and IR spectroscopy. The reaction is second order viz. first order with respect to each reactant. Activation parameters have also been evaluated. A plausible reaction mechanism is mentioned and the derived kinetic rate law accounts for experimental observations.
\end{abstract}

Key words: Kinetics, Mechanism, Oxidation, Nicotinic acid, Peroxomonosulfate

\section{INTRODUCTION}

Peroxomonosulfate (heretofore written as PMS) in aqueous solution to be $\mathrm{HSO}_{5}{ }^{-}$is an active ingredient of oxone. Oxone is a commercial name of this triple salt of potassium $\left(2 \mathrm{KHSO}_{5} \cdot \mathrm{KHSO}_{4} \cdot \mathrm{K}_{2} \mathrm{SO}_{4}\right)$. Oxone is a versatile and environmentally benign oxidant with wide applications such as bleaching, cleaning and disinfection agent. ${ }^{1}$ It has also been employed as an oxidant to degrade the pollutants. $\mathrm{Co}^{2+}$ is the most efficient catalyst of peroxomonosulfate to generate sulfate free radicals. ${ }^{2}$ The catalytic decomposition of PMS in the presence of transition metal ions such as $\mathrm{Mn}^{2+}, \mathrm{Cu}^{2+}, \mathrm{Fe}^{3+} \mathrm{Co}^{2+}$ and biomimetic catalyst like ironporphyrin complex are also reported.,

Peroxomonosulfuric acid - a derivative of hydrogen peroxide when one of the hydrogens of the latter is replaced by sulfuric acid group. ${ }^{5-7}$ Thus it is this weak peroxide linkage (-O-O-) that undergoes cleavage during electron transfer reactions. ${ }^{8-15}$ However, such peroxocompounds are exceptionally sensitive to the traces of metal-ions as has been observed in trace metal-ion catalysis in large number of reactions of peroxo acids. ${ }^{16}$

The structure of peroxomonosulfate is consistent with one proton being ionised and other proton undergoes hydrolysis. Edwards et al. ${ }^{17,18}$ studied decomposition of peroxomonosulfate over a limited $\mathrm{pH}$ range. Robson et al. ${ }^{19}$ reported similar kinetics of uncatalysed decomposition of peroxoaromatic compounds as well as peroxomonosulfate and suggested nucleophilic attack of $\mathrm{SO}_{5}{ }^{-2}$ on the sulphur atom of $\mathrm{HSO}_{5}{ }^{-}$. Peroxomonosulfuric acid ${ }^{20-22}$ as nucleophile in oxidation of various organic compounds has also been reported.

These were the studies that stimulated our interest to explore kinetics of oxidation of nicotinic acid by PMS to understand its reducing properties which are hitter to least known. It is expected that its reactivity pattern in aqueous acid medium can provide additional information about the chemistry of this organic acid in particular and peroxomonosulfate in general.

\section{EXPERIMENTAL}

\section{Materials and Methods Materials:}

Peroxomonosulfate (Aldrich) was employed as received. The solution of peroxomonosulfate was prepared by dissolving its potassium salt $\left(\mathrm{K}_{2} \mathrm{SO}_{5} \cdot \mathrm{KHSO}_{4} \cdot \mathrm{K}_{2} \mathrm{SO}_{4}\right)$ in doubly distilled water. The solution of PMS was standardized both iodometrically and ceremetrically respectively and an impurity owing to $\mathrm{KHSO}_{4}$ or $\mathrm{K}_{2} \mathrm{SO}_{4}$ or both did not exceed more than 4\%. However, the kinetic results were not affected by such an impurity. Efforts were also made to purify the salt but were not successful. Other reagents were either of AnalaR or guaranteed reagent grade and were employed as received. Doubly distilled water was employed throughout the study; second distillation was from alkaline permanganate solution in an all glass apparatus. Nevertheless, a few reactions were also carried out in tripply distilled water (redistilling of double distilled water in the presence of edta) to check trace metal-ion catalysis. Since trace metal-ion catalysis is reported in reactions of per-acid. However, catalysis of this type was 
not observed in this reaction under experimental conditions of the kinetics.

\section{Kinetic Procedure}

All the ingredients of the reaction except peroxomonosulfate were taken in glass stoppered Corning glass vessels which were suspended in a water-bath thermostated at $\pm 0.1{ }^{\circ} \mathrm{C}$ unless specified otherwise. The reaction was initiated by adding temperature pre-equilibrated PMS solution into reaction mixture and the time of initiation was recorded when pipette was half emptied. The kinetics of the reaction was monitored iodometrically by withdrawing an aliquot $\left(5 \mathrm{~cm}^{3}\right)$ of the reaction mixture periodically and then discharging it in to ice-cold potassium iodide solutions $(\sim 10 \%)$. The liberated iodine was titrated against sodium thiosulfate solution using starch as an indicator.

Initial rates $\left(\mathrm{k}_{\mathrm{i}}, \mathrm{mol} \mathrm{dm}^{-3} \mathrm{~s}^{-1}\right)$ were computed employing plane mirror method. Pseudo first order plots were also made (Nic Acid is heretofore written for the nicotinic acid) wherever reaction conditions were such as [Nic. Acid] $>>$ [PMS]. Results in triplicate were reproducible to within $\pm 6 \%$

\section{Stoichiometry}

The stoichiometry of the reaction was determined by allowing reactions in a thermostated water bath for $\mathrm{Ca} .12 \mathrm{~h}$ at $35^{\circ} \mathrm{C}$. The excess concentration of peroxomonosulfate was determined iodometrically. These stoichiometric results correspond to the reaction of one mole of nicotinic acid to a mole of peroxomonosulfate as represented by eqn (1)

$$
-{ }^{-} \mathrm{OOC}-\mathrm{C}_{5} \mathrm{H}_{5} \mathrm{~N}+\mathrm{HSO}_{5}^{-} \longrightarrow{ }^{-}{ }^{-} \mathrm{OOC}-\mathrm{C}_{5} \mathrm{~N}_{5} \mathrm{~N} \rightarrow \mathrm{O}+\mathrm{HSO}_{4}^{-}
$$

\section{Product Analysis}

The oxidation product to be N-oxide of nicotinic acid to be N-Oxide was identified by U.V.-visible spectrophotometric (Fig. 1) where observed $\lambda_{\max }$ at $254 \mathrm{~nm}$ is characteristic of $\mathrm{N} \rightarrow \mathrm{O}$ product of nicotinic acid. The IR spectrum (Fig. 2) of the reaction mixture in KRS cell shows strong peak in the $1640-1680 \mathrm{~cm}^{-1}$ conforming the product. Thus the stoichiometric, UV-visible and IR spectral results confirm conversion of nicotinic acid to $\mathrm{N} \rightarrow \mathrm{O}$ form of nicotinic acid. Such a product is not unique in the light of the fact that the hydrogen peroxide being relatively much weaker oxidizing agent than PMS has limited conversion of tertiary amines to their $\mathrm{N}$-oxides. ${ }^{23}$

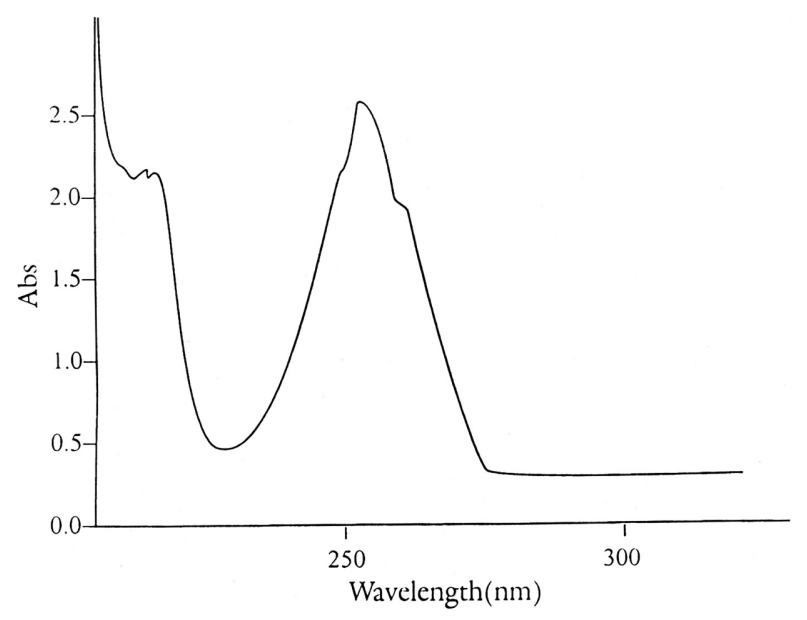

Fig. 1. U.V.-visible spectrum of N-Oxide nicotinic acid in a reaction of nicotinic acid and peroxomonosulphate in acetate buffers.

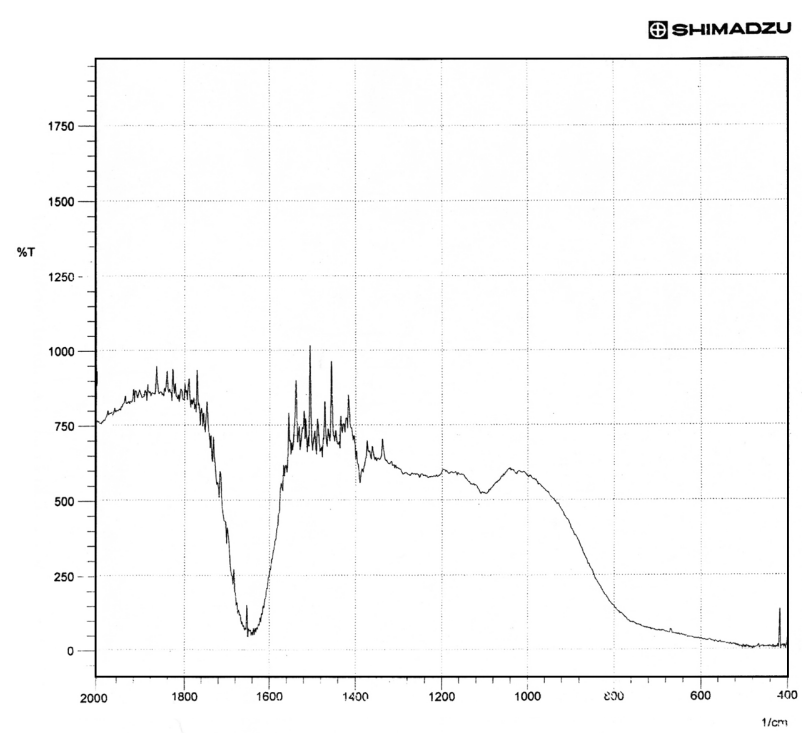

Fig. 2. N-Oxide nicotinic acid IR spectrum in a reaction of nicotinic acid and peroxomonosulphate in acetate buffers.

\section{RESULTS}

\section{Peroxomonosulfate (PMS) and Nicotinic Acid (Nic.Acid) Dependence}

The concentration of peroxomonosulfate was varied at constant concentrations of [Nic acid] $=2.0 \times 10^{-2}, 3.0 \times 10^{-2}$, $4.0 \times 10^{-2}$ and $5.0 \times 10^{-2} \mathrm{~mol} \mathrm{dm}^{-3}$ respectively, $\mathrm{pH} 4.02$ and $35^{\circ} \mathrm{C}$. Pseudo first order plots were made (Fig. 3) and evaluated pseudo first order rate constants $\left(\mathrm{k}^{\prime}, \mathrm{s}^{-1}\right)$ from these plots were found to be independent of gross initial concentrations of the oxidant conforming first order with respect to peroxomonosulfate (Table 1).

The concentration of nicotinic acid was varied at fixed concentrations of other reaction ingredients and $[\mathrm{PMS}]=$ 


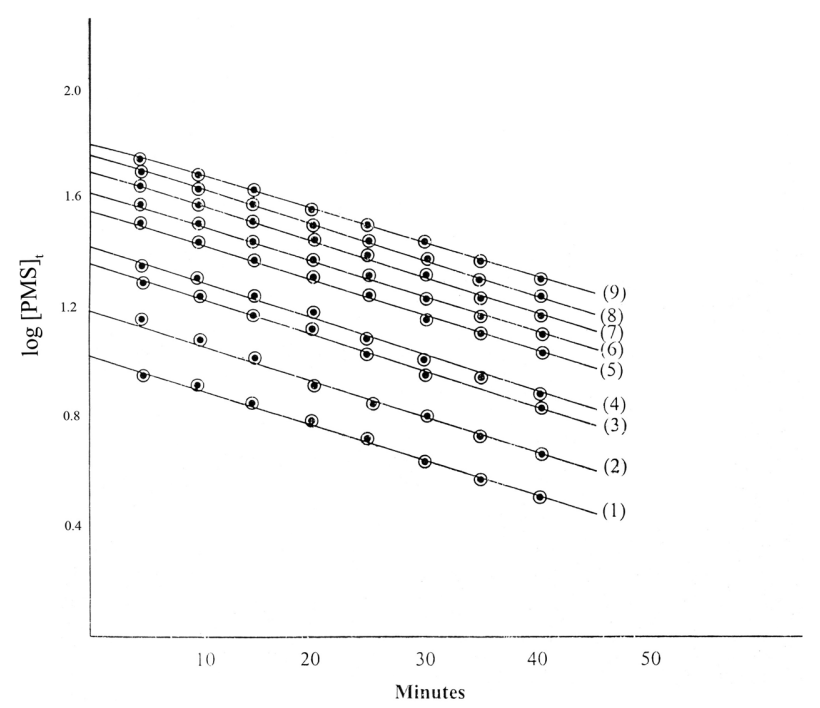

Fig. 3. Pseudo first order plot in the reaction of nicotinic acid and peroxomonosulphate. [Nic acid] $=5.0 \times 10^{-3} \mathrm{~mol} \mathrm{dm}^{-3} ; \mathrm{pH}=$ 4.02 and $35^{\circ} \mathrm{C}$. $[\mathrm{PMS}]=1.0 \times 10^{-3}(1) ; 1.5 \times 10^{-3}(2) ; 2.0 \times 10^{-3}(3)$; $2.5 \times 10^{-3}(4) ; 3.0 \times 10^{-3}(5) ; 3.5 \times 10^{-3}(6) ; 4.0 \times 10^{-3}(7)$; and $5 \times 10^{-3}$ $\mathrm{mol} \mathrm{dm} \mathrm{dm}^{-3}(8)$.

$2.0 \times 10^{-3}$ and $3.0 \times 10^{-3} \mathrm{~mol} \mathrm{dm}^{-3}$ respectively, $\mathrm{pH} 4.02$ and $35^{\circ} \mathrm{C}$.

Initial rates $\left(\mathrm{k}_{\mathrm{i}}, \mathrm{mol} \mathrm{dm}^{-3} \mathrm{~s}^{-1}\right)$ were computed employing plane mirror method. ${ }^{24}$ The plot of $\mathrm{k}_{\mathrm{i}}$ versus concentration of nicotinic acid yielded a straight line passing through the origin conforming first order dependence with respect to the substrate. Further, pseudo first order plots were also made and a plot of pseudo first order rate constants $\left(\mathrm{k}^{\prime}, \mathrm{s}^{-1}\right)$ against the concentration of nicotinic acid also yields a straight line passing through the origin confirming first order with respect to nicotinic acid.

Since the reaction is second order viz. first order with respect to each reactant, second order plots of $\log [\mathrm{PMS}]_{t} /$ $[\mathrm{Nic} \text { Acid }]_{\mathrm{t}}$ or $\log [\mathrm{Nic} \text { Acid }]_{\mathrm{t}} /[\mathrm{PMS}]_{\mathrm{t}}$ versus time were also made and the second order rate constants obtained from such plots were found in agreement with the second order rate constants obtained from initial rates and pseudo first order rate constants respectively (Table 1).

The $\mathrm{pH}$ variation was made by changing the composition of acetate buffers at fixed concentration of sodium acetate and also keeping concentrations of other reaction ingredients constant at 30,35 and $45^{\circ} \mathrm{C}$ respectively. The $\mathrm{pH}$ of the reaction mixture was checked employing digital $\mathrm{pH}$ meter prior to and after the reaction. The maximum change in $\mathrm{pH}$ was of 0.01 units. The rate, however, increases with increasing $\mathrm{pH}$ of the reaction.

The effect of temperature on the rate was studied at 30 , 35 and $40{ }^{\circ} \mathrm{C}$ respectively and $\mathrm{pH}, 4.02$ keeping constant
Table 1. Initial rate constants $\left(\mathrm{k}_{\mathrm{i}}, \mathrm{mol} \mathrm{dm}^{-3} \mathrm{~s}^{-1}\right)$ pseudo first order rate constants $\left(\mathrm{k}^{\prime}, \mathrm{s}^{-1}\right)$ and second order rate constants $\left(\mathrm{k}, \mathrm{dm}^{3} \mathrm{~mol}^{-1} \mathrm{~s}^{-1}\right)$ in the reaction of nicotinic acid by peroxomonosulphate in acid medium. $\mathrm{pH}=4.02$ and $35^{\circ} \mathrm{C}$

\begin{tabular}{cccc}
\hline $\begin{array}{c}10^{3}[\mathrm{PMS}] \\
\left(\mathrm{mol} \mathrm{dm}^{-3}\right)\end{array}$ & $\begin{array}{c}10^{2}[\mathrm{Nic} \mathrm{acid}] \\
\left(\mathrm{mol} \mathrm{dm}^{-3}\right)\end{array}$ & $\begin{array}{c}10^{4}\left[\mathrm{k}^{\prime}\right] \\
\left(\mathrm{s}^{-1}\right)\end{array}$ & $\begin{array}{c}10^{2}[\mathrm{k}] \\
\left(\mathrm{dm}^{3} \mathrm{~mol}^{-1} \mathrm{~s}^{-1}\right)\end{array}$ \\
\hline 1.0 & 2.0 & 2.11 & $1.0 \pm 0.1(1.0 \pm 0.1)$ \\
2.0 & 2.0 & 2.11 & $1.0 \pm 0.1(1.0 \pm 0.1)$ \\
1.0 & 3.0 & 3.26 & $1.0 \pm 0.1(1.1 \pm 0.1)$ \\
2.0 & 3.0 & 3.26 & $1.0 \pm 0.1(1.1 \pm 0.1)$ \\
3.0 & 3.0 & 3.26 & $1.1 \pm 0.1(1.1 \pm 0.1)$ \\
1.0 & 4.0 & 4.22 & $1.0 \pm 0.1(1.0 \pm 0.1)$ \\
2.0 & 4.0 & 4.22 & $1.1 \pm 0.1(1.1 \pm 0.1)$ \\
3.0 & 4.0 & 4.22 & $1.0 \pm 0.1(1.0 \pm 0.1)$ \\
4.0 & 4.0 & 4.22 & $1.0 \pm 0.1(1.0 \pm 0.1)$ \\
1.0 & 5.0 & 5.3 & $1.0 \pm 0.1(1.0 \pm 0.1)$ \\
2.0 & 5.0 & 5.3 & $1.0 \pm 0.1(1.0 \pm 0.1)$ \\
3.0 & 5.0 & 5.3 & $1.0 \pm 0.1(1.1 \pm 0.1)$ \\
4.0 & 5.0 & 5.3 & $1.1 \pm 0.1(1.1 \pm 0.1)$ \\
5.0 & 5.0 & 5.3 & $1.0 \pm 0.05(1.1 \pm 0.1)$ \\
2.0 & 20.0 & 2.11 & $1.1 \pm 0.1(1.1 \pm 0.1)$ \\
2.0 & 30.0 & 3.26 & $1.1 \pm 0.15(1.1 \pm 0.15)$ \\
2.0 & 40.0 & 4.22 & $1.0 \pm 0.1(1.1 \pm 0.1)$ \\
2.0 & 50.0 & 5.3 & $1.0 \pm 0.1(1.0 \pm 0.1)$ \\
\hline
\end{tabular}

$\overline{\text { Figures in parentheses were obtained from pseudo first order rate }}$ constants.

concentrations of other reaction ingredients.

The energy and entropy of activation were calculated to be $(50 \pm 3.0) \mathrm{kJ} \mathrm{mol}^{-1}(-98 \pm 7) \mathrm{JK}^{-1} \mathrm{~mol}^{-1}$ respectively in a conventional manner. The experimental energy of activation is of the same order as is usually found in second order reactions. Such a (-)ve entropy of activation is generally assigned to more rigid associative transition state.

\section{DISCUSSION}

The overall reaction is second order exhibiting first order with respect to oxidant and substrate respectively. Since the rate is retarded by hydrogen ion concentration, the salient feature of the reaction is to co-relate hydrogen ion concentration either to the oxidant or substrate or both. Peroxomonosulfate in aqueous solution is governed by equilibrium (2)

$$
\mathrm{HSO}_{5}^{-} \rightleftharpoons \mathrm{SO}_{5}^{2-}+\mathrm{H}^{+}
$$

$\mathrm{pK}_{1}$ and $\mathrm{pK}_{2}$ of PMS, if, taken into account, $\mathrm{HSO}_{5}{ }^{-}$species is predominant at $\mathrm{pH}<0$ whereas $\mathrm{SO}_{5}{ }^{2-}$ species exhibits its predominance only at $\mathrm{pH}>9$. Therefore if $\mathrm{pK}_{1}$ and $\mathrm{pK}_{2}$ are any guide, the $\mathrm{pH}$ effect can not be co-related to $\mathrm{PMS}$ and $\mathrm{SO}_{5}^{2-}$ species. Since, nicotinic acid is proto- 
nated under experimental conditions as in equilibrium (3), hydrogen ion dependence can be co-related to nicotinic acid and as such nicotinic acid appears to be the reactive species. Thus considering $\mathrm{HSO}_{5}{ }^{-}$and molecular form of nicotinic acid to be the reactive forms of oxidant and substrate respectively, the following reaction mechanism consisting of steps (3)-(5) can be envisaged to account for the experimental results.<smiles></smiles><smiles>O=C([O-])c1cccnc1</smiles>

[Adduct] $^{\#} \stackrel{k^{\prime}}{\longrightarrow}$ Products

The loss of peroxomonosulfate leads to the rate law (6) or (7)

$$
-\frac{\mathrm{d}[\mathrm{PMS}]}{\mathrm{dt}}=\frac{\mathrm{k}^{\prime} \mathrm{K}_{2}[\mathrm{Nic} \text { acid }][\mathrm{PMS}]}{\mathrm{K}_{1}+\left[\mathrm{H}^{+}\right]}
$$

Where [Nic acid] and [PMS] are the gross analytical concentrations of nicotinic acid and peroxomonosulfate respectively.

or

$$
\mathrm{k}=\frac{\mathrm{k}^{\prime} \mathrm{K}_{2}}{\mathrm{~K}_{1}+\left[\mathrm{H}^{+}\right]}
$$

Where ' $\mathrm{k}$ ' is an observed second order rate constant (Table 1). The double reciprocal of equation (7) yields equation (8).

$$
\frac{1}{\mathrm{k}}=\frac{\mathrm{K}_{1}}{\mathrm{k}^{\prime} \mathrm{K}_{2}}+\frac{\left[\mathrm{H}^{+}\right]}{\mathrm{k}^{\prime} \mathrm{K}_{2}}
$$

A plot of $1 / \mathrm{k}$ versus $\left[\mathrm{H}^{+}\right]$was made from eqn. (8) that yielded a straight line with non-zero intercept (Fig. 4).

' $\mathrm{K}_{1}$ ' was calculated from the ratio of intercept and slope to be $2.5 \times 10^{-5}, 2.0 \times 10^{-5}$ and $1.6 \times 10^{-5}$ at 30,35 and $40{ }^{\circ} \mathrm{C}$ respectively.

Since these values are of the order of $\mathrm{pK}_{1} \simeq 6$, which is expected for such a weak acid like that of nicotinic acid.

The reaction species $\mathrm{HSO}_{5}{ }^{-}$is more reactive than $\mathrm{SO}_{5}{ }^{2-}$

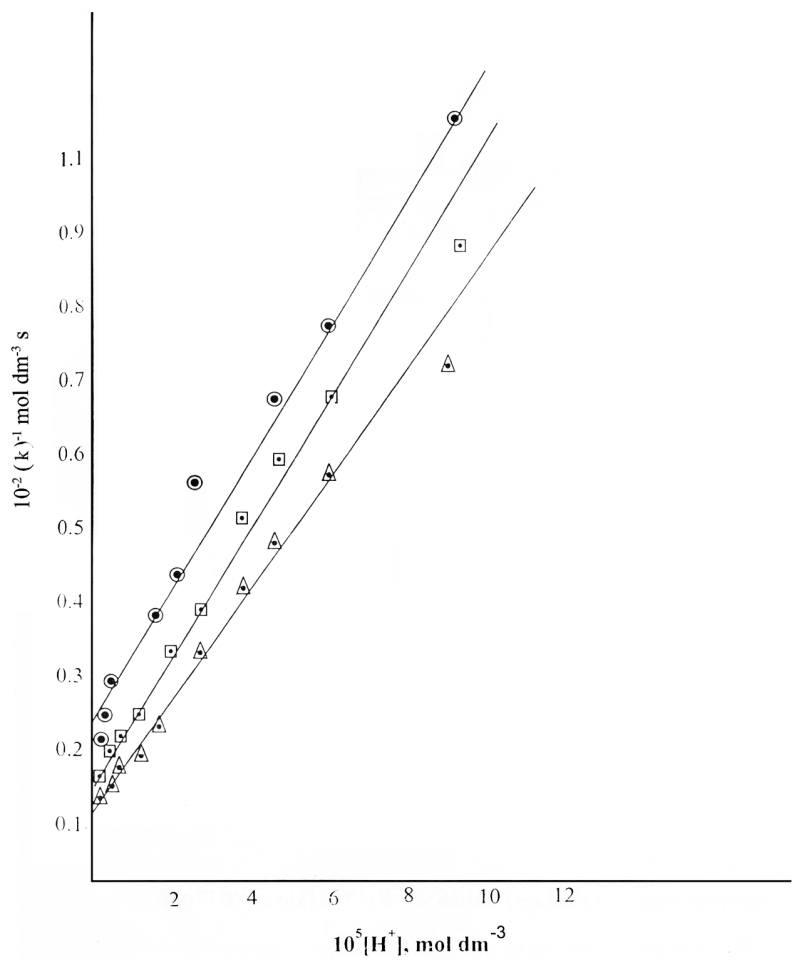

Fig. 4. A plot of $(\mathrm{k})^{-1}$ versus $\left[\mathrm{H}^{+}\right]$. $[\mathrm{Nic}$ Acid $]=4 \times 10^{-2}$; $[\mathrm{PMS}]=$ $3 \times 10^{-3} ;\left[\mathrm{NaNO}_{3}\right] 0.5 \times 10^{-3} \mathrm{~mol} \mathrm{dm}^{-3} ; \bigcirc, 30^{\circ} \mathrm{C} ; \bullet, 35^{\circ} \mathrm{C} ; \stackrel{\Delta}{\mathrm{O}}, 40^{\circ} \mathrm{C}$.

species; the former is more electrophilic than the latter species. This involves nucleophilic attack of the nitrogen lone pair on the electrophilic peroxo oxygen of peroxomonosulfate species similar to $\mathrm{S}_{\mathrm{N}}{ }^{2}$ type transition state as suggested earlier. ${ }^{14,16-18}$<smiles>CCN1CCCC(C(=O)[O-])C1</smiles>

\section{CONCLUSIONS}

The reaction of nicotinic acid and peroxomonosulfate at acidic $\mathrm{pH}$ yields $\mathrm{N} \rightarrow \mathrm{O}$ nicotinic acid based on stoichiometric results and product analysis both by UV and IR spectral analysis.

The oxidation of nicotinic acid by peroxomonosulfate in acid medium exhibits second order viz. first order with respect to each reactant. Hydrogen ion retards the rate of the reaction and such retardation can be assigned to acid- 
base equilibrium of nicotinic acid. The proposed mechanism accounts for the experimental observations and the rate law.

\section{REFERENCES}

1. Ermer, O.; Robke, C. Helv. Chim. Acta 2003, 86, 2908.

2. Chen, X.; Qiao, X.; Wang, D.; Lin, J.; Chen, J. Chemosphere 2007, 67, 802.

3.Fukushima, M.; Ichikawa, H.; Kawasaki, M.; Sawada, A.; Morimoto, K.; Tatsumi, K. Environ. Sci. Technol. 2003, $37,386$.

4. Fernandez, J.; Maruthamuthu, P.; Kiwi, J. J. Photochem. Photobiol A: Chem. 2004, 161, 185.

5. Spiro, M. Electrochim. Acta 1979, 24, 313.

6. Ball, D. L.; Edwards, J.O. J. Am. Chem. Soc. 1956, 78, 1125.

7. Kolthoff, I. M.; Miller, I. K. J. Am. Chem. Soc. 1951, 73, 3055 .

8. Madhavan, J.; Maruthamuthu, P.; Murugesan, S. AshokKumar, M. Appl. Catal., A General 2009, 368, 35.

9. Murugavelu, M.; Andal, P.; Shailaja, S.; Ramachandran, M. S. J. Mol. Catal. A: Chem. 2009, 306, 1.

10. Mehrotra, M.; Mehrotra, R. N. Polyhedron 2008, 27, 2151.

11. Lente, G.; Fabian, J. J. Chem. Soc. Daltan Trans. 2007,
$38,4268$.

12. Dubey, S.; Hemkar, S.; Khandelwal, C. L.; Sharma, P. D. Inorg. Chem. Commun. 2002, 5, 903.

13. Balakrishnan, T.; Damodarkumar, S. J. Appl. Polymer Science 2000, 76, 1564.

14. Rani, S. K.; Easwaramoorthy, D.; Bilal, I. M.; Palanichamy, M. Appl. Catal., A General 2009, 369, 1.

15. Khalid, M. A. A. Arabian J. Sciences and Engin. 2008, 33, 199.

16. Edwards, J. O., Ed. Peroxide Reaction Mechanisms; Interscience: New York, 1962; pp 67-106.

17. Koubek, E.; Levey, G.; Edwards, J. O. Inorg. Chem. 1964, 3, 1331.

18. Curci, R.; Edwards, J. O. In Organic Peroxides: Swern, D., Ed.; Wiley Intersciences: New York, 1970; Vol. 1, pp 199-264.

19. Goodman, J. F.; Robson, P. J. Chem. Soc. 1963, 2871.

20. Jameel, A. A.; Maruthamuthu, P. J. Ind. Chem. Soc. 1998, $75,368$.

21. Panda, R. S.; Panigrahi, A. K.; Patnaik, C. P.; Sahu, S. K.; Mahapatra, S. K. Bull. Chem. Soc. Jpn. 1988, 61, 1363.

22. Panda, R. S.; Patnaik, C. P.; Mohapatro, S. N.; Panigrahi, A. K. Bull. Chem. Soc. Jpn. 1987, 60, 3391.

23. Payne, G. B.; Deming, P. H.; Williams, P. H. J. Org. Chem. 1961, 26, 659. 